Research Paper

\title{
Impact of tumour size on metastasis and survival in patients with pancreatic neuroendocrine tumours (PNETs): A population based study
}

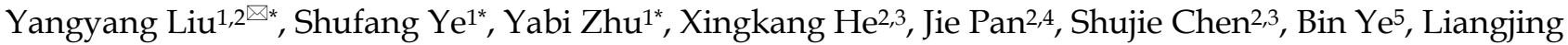 \\ Wang $2,6 \bowtie$ \\ 1. Department of Gastroenterology, Sixth Affiliated Hospital of Wenzhou Medical University, Lishui People's Hospital, Lishui, Zhejiang Provine, China \\ 2. Institution of Gastroenterology, Zhejiang University, Hangzhou, Zhejiang Province, China \\ 3. Department of Gastroenterology, Sir Run Run Shaw Hospital, Zhejiang University, Hangzhou, Zhejiang Province, China Department of Gastroenterology, \\ Zhejiang University Lishui Hospital, \\ 4. Department of Endocrinology and metabolism, Second Affiliated Hospital of Zhejiang University School of Medicine, Hangzhou, Zhejiang Province, China \\ 5. Department of Gastroenterology, Lishui Municipal Central Hospital, Lishui, Zhejiang Province, China \\ 6. Department of Gastroenterology, Second Affiliated Hospital of Zhejiang University School of Medicine, Hangzhou, Zhejiang Province, China \\ *These authors contributed equally to this article. \\ $\triangle$ Corresponding author: Liangjing Wang, Department of Gastroenterology, Second Affiliated Hospital of Zhejiang University School of Medicine, 88 Jiefang \\ Road, Hangzhou, 310009, Zhejiang Province, China; E-mail: Wangljzju@zju.edu.cn and Yangyang Liu, Department of Gastroenterology, Sixth Affiliated \\ Hospital of Wenzhou Medical University, Lishui People's Hospital, No.15 Dazhong Road, Lishui, 323000, Zhejiang Province, China; E-mail: liu_chit@163.com.
}

(C) The author(s). This is an open access article distributed under the terms of the Creative Commons Attribution License (https://creativecommons.org/licenses/by/4.0/). See http://ivyspring.com/terms for full terms and conditions.

Received: 2019.03.09; Accepted: 2019.09.26; Published: 2019.10.18

\begin{abstract}
Background: The relationship between tumour size and metastasis rate is poorly recognized in patients with pancreatic neuroendocrine tumours (PNETs). The impact of tumour size on prognosis was controversial in previous investigations.

Methods: PNETs cases diagnosed from 1988 to 2013 were retrieved from the Surveillance, Epidemiology, and End Results (SEER) database. Clinicopathologic features were retrospectively analyzed. Survival was calculated by the Kaplan-Meier method. Multivariable Cox regression models with hazard ratios (HRs) were constructed to analyze survival outcomes and risk factors. Cubic spline analysis was used to assess relationship between tumor size and probability of metastasis.

Results: A total of 5424 patients were identified, 1226 (22.6\%) with tumour size of $20 \mathrm{~mm}$ or less. The probability of metastasis increased in a non-linear fashion with increasing tumour size. Univariate analysis showed that tumour size was significantly correlated with survival $(P<0.001)$, no matter surgery was performed or not. However, subgroup analysis suggested this association to be linear for patients with localized and regional tumours $(P<0.001)$, but stochastic in patients with distant stages $(P=0.703)$. On multivariate analysis, tumour size was an indicator for metastasis $(\mathrm{HR}=1.010,95 \% \mathrm{Cl}$ : $1.008-1.013, P<$ 0.001 ) and size $\leq 20 \mathrm{~mm}$ was an independent prognostic factor for good survival. For tumours $\leq 20 \mathrm{~mm}$, surgical treatment was associated with significantly improved survival $(P<0.001)$.

Conclusions: Tumour size affects the probability of metastasis. Its prognostic impact on survival is restricted to patients with localized and regional disease. For patients with tumour size $\leq 20 \mathrm{~mm}$, surgical treatment should be considered preferably.
\end{abstract}

Key words: tumour size, pancreatic neuroendocrine tumours, PNETs, metastasis, survival

\section{Introduction}

Neuroendocrine tumours (NET) consist of a diverse group of neoplasms that derive from diffuse neuroendocrine cells throughout the body[1].
Commonly found in gastrointestinal (GI) duct and lung, they also arise in the pancreas. Pancreatic neuroendocrine tumours (PNETs) are relatively rare, 
accounting for approximately $7 \%$ of all neuroendocrine tumours, and $<3 \%$ of overall pancreatic tumours[2,3]. According to data from the National Cancer Institute Surveillance, Epidemiology, and End Result (SEER) registry, the overall incidence is 0.43 cases per 100,00 inhabitants, which has more than doubled in the past 20-30 years[2,4]. This is partially due to the increased physician awareness, improvements in recognition of neuroendocrine histology and advances of diagnostic techniques[1].

PNETs exhibit heterogeneous biologic behavior, ranging from indolent to aggressive based upon specific histology which may include the elaboration of active gastrointestinal hormones[1]. Depending on the presence or absence of clinical syndromes resulting from an inapproapriate hormone secretion, PNETs are divided into 'functional' and 'non-functional' subgroups. About $60-90 \%$ of patients are non-functional, largely asymptomatic. In contrast, functional PNETs have variable clinical presentations caused by different hormones, such as insulin, gastrin, vasoactive intestinal peptide(VIP), glucagon, somatostatin and secroton[5].

Given the heterogenous nature of PNETs, efforts to identify reliable prognostic features have been a challenge. Tumour size is one of these essential values. The proposed American Joint Committee on Cancer (AJCC) and European Neuroendocrine Tumours Society (ENETS) classifications have defined disease stage based on size of primary tumour[6,7]. However, validation of these systems has been conflicting, and tumour size has not been shown to be significantly predictive of survival in several studies $[8,9,10]$. Even more, Kuo and his colleagues reported a relatively high rate of metastasis in small tumours[11]. Nonetheless, the metastatic rate of PNETs of all sizes has not been reported before.

Surgical resection is the only potentially curative therapy for PNETs, and palliative surgery is also an accepted course of action in cases of liver metastatic disease[12,13]. However, for tumours no larger than $20 \mathrm{~mm}$, surgical treatment remains to be controversial. As stated in the ENETS guidelines[14] and some scientific literatures, conservative approach was recommended to be safe[15,16,17], while some others reported that long-term outcome of resected patients were better than those with non-operative treatment[18].

Most of the above studies have been based on data from single-center institutions. The aim of the present study is to investigate the relationship between primary tumour size and metastatic rates and survival in patients with PNETs, and to explore the impact of surgical intervention on tumours $\leq 20 \mathrm{~mm}$ using a population-based registry.

\section{Materials and Methods}

\section{Data source}

The SEER registry database, sponsored by the National Cancer Institute was used for this study. It includes over three million cases from 18 geographic sites among 14 states from the USA, representing approximately $30 \%$ of the US population. The SEER database records patient demographics (e.g. age and sex), primary tumour characteristics (e.g. size, extent and grade), nodal staging (number of nodes examined and number of involved nodes), primary operation performed, vital status and survival. The July 2016 update was used for this study, providing information from 1973 to 2013[19]. Quality control is an important component of the SEER program, and the current standard for accuracy of the data in the registry is an error rate of less than 5\%[19]. We have got permission to access the research data file using SEER ${ }^{*}$ Stat version 8.3.2 and the reference number was 12907-Nov2015. This study was approved by the Institutional Review Board.

\section{Inclusion and Exclusion Criteria}

As detailed tumour size was not recorded before 1988, our study group included all patients with PNETs registered in the SEER database between 1988 and 2013. Patients diagnosed after 2013 were excluded to ensure an adequate duration of followup. The specific inclusion criteria were as follows: 1 ) the years of diagnosis ranged from 1988 to 2013. 2) the International Classification of Disease for Oncology (3rd edition) site record was limited to the following items: islet cell carcinoma (8150), insulinoma (8151), glucagonoma (8152), gastrinoma (8153), mixed isletcell/exocrine adenocarcinoma (8154), vipoma (8155), somatostatinoma (8156), carcinoid (8240), enterochromaffin cell carcinoid (8241), enterochromaffin-like cell tumors (8242), goblet cell carcinoid (8243), composite carcinoid (8244), adenocarcinoid (8245), neuroendocrine carcinoma (8246), and atypical carcinoid (8249). 3) site record ICD-O-3 was limited to the pancreas. 4) patients with histologically confirmed disease and tumour of all grades were included in the analysis. 5) Tumour size was measured as the maximum length of the tumour based on the pathological, operative or radiological report, in this order of priority. The exclusion criteria were as follows: 1 ) patients with a lack of documentation of their race, marital status, or age at diagnosis were excluded; 2) patients with incomplete follow-up were removed.

The following factors were retrieved from the SEER database: the year and age at diagnosis, sex, race, tumour stage, site record, histological grade, surgical resection, regional nodes positive, tumour 
size, metastasis, survival months, vital status.

In order to ensure a coherent cancer staging classification across the study period, the "SEER historical stage" was used, which provides a consistent definition over time. It is a coding schema with 3 clinically relevant categories: localized, regional, or distant disease. Although the AJCC staging system was more widely used in clinical practice, it was not accessible for many of the annual data sets analyzed.

\section{Statistical analysis}

Incidence rates per 100,000 were calculated using SEER*Stat. Univariate analyses comparing patient demographics and tumor characteristics were performed. Survival curves were calculated using the Kaplan-Meier method, and the log-rank test was carried out to evaluate the survival differences between groups. Risk factors with a $P$ value $<0.1$ in the univariable analysis were entered into the multivariable analysis. The Cox proportional hazards model was built to calculate adjusted hazard ratios (HRs) along with 95\% confidence intervals (CIs), which were used to assess the strength of the individual variables. To graphically demonstrate a relationship between tumour size and probability of metastasis, cubic spline analysis was conductedwhich makes no assumption about the relationship between parameters and is entirely data-driven. Logistic regression was used to assess the prognostic value of tumour size for the presence of metastasis. Data was analyzed using IBM SPSS Statistics version 23.0 for Microsoft (IBM Corp. Armok, NY, USA). When the two-sided $P$-value was less than 0.05 , the difference was considered statistically significant.

\section{Results}

\section{Demographics and tumour characteristics}

In total, 7074 patients with PNETs were registered in the SEER database during the 25 years study period. Some 1650 patients did not fulfill the inclusion criteria, not available for detailed information on follow-up or tumour size and were excluded. Finally, 5424 eligible patients were included in the study group and were used for further calculations. They comprised about 77\% (5424/7074) of the total number of PNETs. The annual incidence rate of this disease was significantly increasing over time, from $0.21 / 100,000$ in 1988 to $3.01 / 100,000$ in 2013 (Figure 1). Patients and detailed tumour characteristics are summarized in Table 1. Briefly, most patients were white $(80.5 \%)$, with a male predominance (male: female $=1.24$ ) and a median age of 61 years old (interqurtile range, IQR: 50-71). A total of 4279 patients $(78.9 \%)$ presented with a functioning tumour, while 1145 (21.1\%) with non-functioning. Tumours were commonly located in pancreatic head $(33.5 \%)$, tail $(31 \%)$, body $(13.8 \%)$. Most patients had metastatic tumours (45\%) at the time of diagnosis, with $31 \%$ had localized disease, $22.4 \%$ had regional disease, and in $1.6 \%$ of patients the disease stage was unknown. The median tumour diameter was $46.2 \mathrm{~mm}$, $22.6 \%$ of the tumours had a diameter of $20 \mathrm{~mm}$ or less, and $44.1 \%$ of the tumours were larger than $40 \mathrm{~mm}$.

Table 1. Clinicopathological characteristics and univariate analysis of patients with pancreatic endocrine tumours in the SEER registry 1988-2013

\begin{tabular}{|c|c|c|c|c|}
\hline \multirow[t]{2}{*}{ Characteristics } & \multirow{2}{*}{$\begin{array}{l}\text { No. of } \\
\text { patients } \\
(n=5424)(\%)\end{array}$} & \multicolumn{2}{|c|}{ Survival (\%) } & \multirow{2}{*}{$\begin{array}{l}P \\
\text { value }^{a}\end{array}$} \\
\hline & & 3-year & 5-year & \\
\hline Age (years) & & & & $<0.001$ \\
\hline$\leq 60$ & $2739(50.5)$ & 71.9 & 61.2 & \\
\hline$>60$ & $2685(49.5)$ & 52.4 & 41 & \\
\hline Race/Ethnicity & & & & 0.007 \\
\hline White & $4364(80.5)$ & 62.5 & 51 & \\
\hline Black & $595(11)$ & 57.5 & 49.3 & \\
\hline Others & $438(8.0)$ & 67.7 & 59.1 & \\
\hline Unknown & $27(0.5)$ & 80 & 80 & \\
\hline Gender & & & & $<0.001$ \\
\hline Female & $2423(44.7)$ & 66.4 & 56 & \\
\hline Male & $3001(55.3)$ & 59.3 & 47.9 & \\
\hline Histology & & & & $<0.001$ \\
\hline Functional tumours (8150 8156) & $1145(21.1)$ & 68 & 56.7 & \\
\hline Nonfunctional tumours (8240 8249) & $4279(78.9)$ & 60.8 & 49.9 & \\
\hline Location of primary tumour & & & & $<0.001$ \\
\hline Head & $1818(33.5)$ & 57.6 & 47 & \\
\hline Body & $746(13.8)$ & 64.4 & 54.2 & \\
\hline Tail & $1687(31.0)$ & 67.9 & 56.1 & \\
\hline Duct & $3(0.1)$ & 33.3 & 33.3 & \\
\hline Islets & $135(2.5)$ & 74.8 & 60.1 & \\
\hline Overlapping & $433(8.0)$ & 61.3 & 49.8 & \\
\hline NOS & $502(9.3)$ & 55.4 & 46.4 & \\
\hline Others & $100(1.8)$ & 74.4 & 69.5 & \\
\hline Grade & & & & $<0.001$ \\
\hline Well differentiated (I) & $1888(34.8)$ & 81.9 & 73.6 & \\
\hline Moderately differentiated (II) & $591(10.9)$ & 72.8 & 61.3 & \\
\hline Poorly differentiated (III) & $366(6.7)$ & 31.6 & 24.5 & \\
\hline Undifferentiated (IV) & $112(2.1)$ & 21 & 16.9 & \\
\hline Unknown & $2467(45.5)$ & 53.9 & 42 & \\
\hline Tumour stage & & & & $<0.001$ \\
\hline Localized & $1681(31)$ & 87.4 & 81.4 & \\
\hline Regional & $1212(22.3)$ & 73 & 62 & \\
\hline Distant & $2441(45)$ & 42.3 & 29.3 & \\
\hline Unstaged & $90(1.7)$ & 63.9 & 54.6 & \\
\hline Surgery & & & & $<0.001$ \\
\hline Yes & $3044(56.1)$ & 84.3 & 74.7 & \\
\hline No & 2365 (43.6) & 35.8 & 24 & \\
\hline Unknown & $15(0.3)$ & 55.8 & 55.8 & \\
\hline Regional lymph nodes & & & & $<0.001$ \\
\hline Positive & $1153(21.3)$ & 74.3 & 62.9 & \\
\hline Negative & $1498(27.5)$ & 86.3 & 77.9 & \\
\hline Unknown & $2773(51.2)$ & 45.6 & 34 & \\
\hline Tumour size & & & & $<0.001$ \\
\hline $0-20 \mathrm{~mm}$ & $1226(22.6)$ & 78.6 & 71.8 & \\
\hline $21-40 \mathrm{~mm}$ & $1806(33.3)$ & 63.1 & 52 & \\
\hline$>40 \mathrm{~mm}$ & $2392(44.1)$ & 55.2 & 43.6 & \\
\hline $\begin{array}{l}\text { Abbreviations: NOS=not otherwise spe } \\
\text { by the Kaplan-Meier method with Log-1 } \\
\text { as statistically significant. }\end{array}$ & $\begin{array}{l}\text { ied. a Univari } \\
\text { k test, } P \text { valu }\end{array}$ & anal & $\begin{array}{l}\text { is was } \\
5 \text { was }\end{array}$ & $\begin{array}{l}\text { lculated } \\
\text { nsidered }\end{array}$ \\
\hline
\end{tabular}




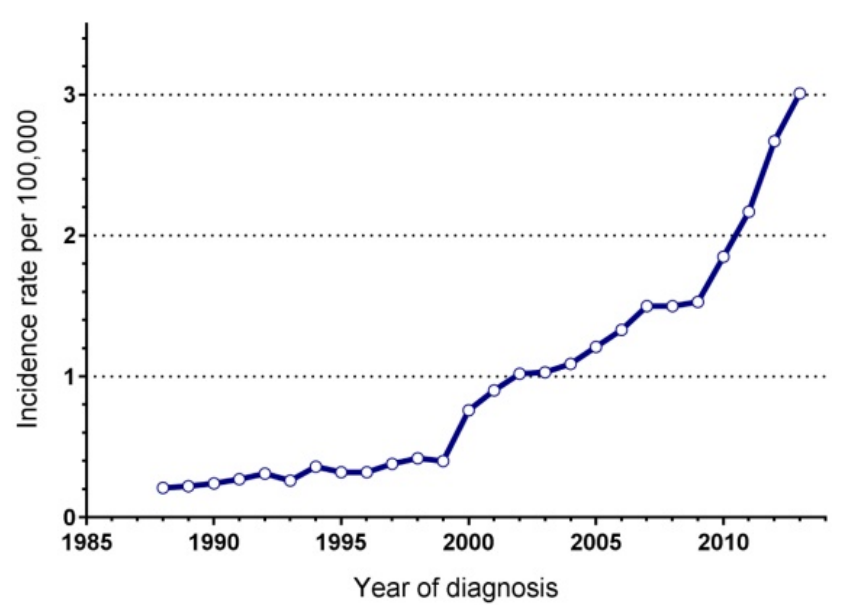

Figure 1. Annual incidence of PNETs, Surveillance, Epidemiology, and End Results registry 1988 to 2013 .

Table 2. Predictors of survival identified by multivariate Cox regression analysis

\begin{tabular}{|c|c|c|c|}
\hline Variables & Hazard ratio & $95 \% \mathrm{CI}$ & $P$ value a \\
\hline \multicolumn{4}{|l|}{ Age (years) } \\
\hline$\leq 60$ & 1.0 (reference) & & \\
\hline$>60$ & 1.784 & $1.640-1.940$ & $<0.001$ \\
\hline \multicolumn{4}{|l|}{ Race/Ethnicity } \\
\hline White & 1.0 (reference) & & \\
\hline Black & 1.076 & $0.943-1.227$ & 0.279 \\
\hline Others & 0.892 & $0.758-1.051$ & 0.172 \\
\hline \multicolumn{4}{|l|}{ Gender } \\
\hline Female & 1.0 (reference) & & \\
\hline Male & 1.047 & $0.963-1.138$ & 0.282 \\
\hline \multicolumn{4}{|l|}{ Histology } \\
\hline $\begin{array}{l}\text { Functional tumours } \\
(8150 \sim 8156)\end{array}$ & 1.0 (reference) & & \\
\hline $\begin{array}{l}\text { Non-functional tumours } \\
(8240 \sim 8249)\end{array}$ & 1.0 & $0.907-1.103$ & 0.998 \\
\hline \multicolumn{4}{|l|}{ Location of primary tumour } \\
\hline Head & 1.0 (reference) & & \\
\hline Body & 0.893 & $0.783-1.028$ & 0.117 \\
\hline Tail & 0.918 & 0.827-1.019 & 0.108 \\
\hline Duct & 3.271 & $1.045-10.239$ & 0.042 \\
\hline Islets & 1.051 & $0.81-1.363$ & 0.708 \\
\hline Overlapping & 0.951 & $0.816-1.108$ & 0.516 \\
\hline \multicolumn{4}{|l|}{ Grade } \\
\hline Well differentiated (I) & 1.0 (reference) & & \\
\hline Moderately differentiated (II) & 1.286 & $1.080-1.531$ & 0.005 \\
\hline Poorly differentiated (III) & 3.040 & $2.581-3.582$ & $<0.001$ \\
\hline Undifferentiated (IV) & 3.576 & $2.807-4.556$ & $<0.001$ \\
\hline \multicolumn{4}{|l|}{ Tumour classification } \\
\hline Localized & 1.0 (reference) & & \\
\hline Regional & 2.054 & $1.739-2.427$ & $<0.001$ \\
\hline Distant & 2.940 & $2.534-3.412$ & $<0.001$ \\
\hline \multicolumn{4}{|l|}{ Surgery } \\
\hline Yes & 1.0 (reference) & & \\
\hline No & 2.713 & $2.354-3.127$ & $<0.001$ \\
\hline \multicolumn{4}{|l|}{ Regional lymph node } \\
\hline Positive & 1.0 (reference) & & \\
\hline Negative & 0.987 & 0.843-1.155 & 0.987 \\
\hline \multicolumn{4}{|l|}{ Tumour size } \\
\hline $0-20 \mathrm{~mm}$ & 1.0 (reference) & & \\
\hline $21-40 \mathrm{~mm}$ & 1.211 & $1.048-1.399$ & 0.009 \\
\hline$>40 \mathrm{~mm}$ & 1.282 & $1.116-1.474$ & $<0.001$ \\
\hline
\end{tabular}

Abbreviations: $\mathrm{CI}=$ confidence interval. a. Multivariate analysis was calculated by the Cox proportional hazards regression model, $P$ value of $<0.05$ was considered as statistically significant.

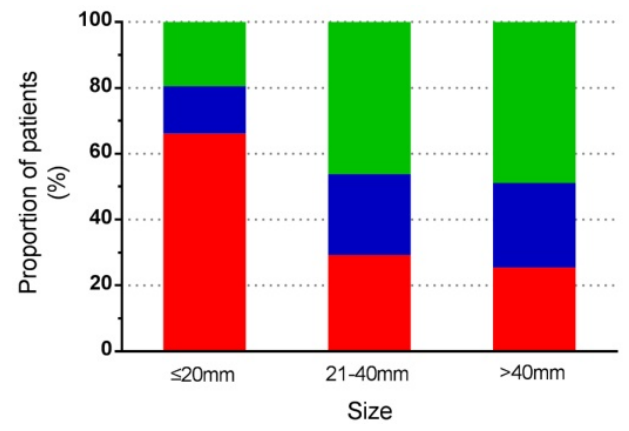

Distant

- Regional

- Localized

Figure 2. Stage distribution according to tumour size.

\section{Survival and prognostic factors}

The median overall survival (OS) for all cases was 21 months (range 0-485months), and we observed that young age ( $\leq 60$ years), race of unknown, female sex, functional tumours, location of others, low tumour grade, localized tumour stage, surgery, negative regional lymph node and small tumour size showed a significant relationship with increasing overall survival based on univariate analysis. Next, we carried out a multivariate analysis, all factors that were associated with survival were included in the Cox-regression model. It showed that the age at diagnosis, tumour grade, tumour stage, surgical resection and tumour size were independent prognostic factors. The tumour stage was the most influential predictor, with the highest HR. However, race, gender, primary site and regional lymph node status were not predictive of outcome (Table 2).

Subgroup analysis was undertaken to determine whether the prognostic impact of tumour size was consistent across stage and treatment categories.

\section{Survival according to tumour size and stage}

Among the included 5424 patients, 90 patients were unstaged. Therefore, a total of 5334 patients were enrolled for further study. Tumour stage distribution according to tumour size is shown in Figure 2. When the tumour size was $\leq 20 \mathrm{~mm}$, the rate of distant metastasis was $19.5 \%$, increasing to $58.9 \%$ when the tumour size was larger than $40 \mathrm{~mm}$. The 5 -year survival rate for the whole study group was $51.5 \%$. For tumours $\leq 20 \mathrm{~mm}$, the 5 -year survival rate was $71.8 \%$, and the rate decreased to $43.8 \%$ in patients with tumours $>40 \mathrm{~mm}$. For patients of localized and regional disease stages, the survival rates decreased with increasing tumour size, while for patients of distant disease stage, tumour size no longer affected the survival rates dramatically (Table 3). Among 1681 patients with local disease only, the 5-year survival rate was $81.4 \%$. It was $87.1 \%$ for patients with tumours of $20 \mathrm{~mm}$ or less in diameter, decreasing to $75 \%$ for those with tumours larger than $40 \mathrm{~mm}$. In 
patients with regional disease, survival was similar across tumour size categories. The relationship between tumour size and survival, stratified by stage, is shown in Figure 3.

Table 3. Tumour size and survival according to disease stage

\begin{tabular}{lllll}
\hline Tumour size (mm) & $\begin{array}{l}\text { No. of } \\
\text { patients (\%) }\end{array}$ & $\begin{array}{l}\text { 3-year } \\
\text { survival (\%) }\end{array}$ & $\begin{array}{l}\text { 5-year } \\
\text { survival (\%) }\end{array}$ & P value \\
\hline All stages & 5334 & 62.5 & 51.5 & $<0.001$ \\
$0--20 \mathrm{~mm}$ & $1205(22.6)$ & 78.7 & 71.7 & \\
20--40 & $1775(33.3)$ & 62.9 & 51.6 & \\
$>40$ & $2354(44.1)$ & 55.2 & 43.8 & \\
Localized disease & 1681 & 87.4 & 81.4 & $<0.001$ \\
$0--20 \mathrm{~mm}$ & $797(47.4)$ & 90.8 & 87.1 & \\
20--40 & $518(30.8)$ & 87.8 & 79.9 & \\
$>40$ & $366(21.8)$ & 80.8 & 75 & \\
Regional disease & 1212 & 73.0 & 62.0 & $<0.001$ \\
$0--20 \mathrm{~mm}$ & $173(14.3)$ & 84 & 75.9 & \\
20--40 & $437(36.1)$ & 74.5 & 64.3 & \\
$>40$ & $602(49.7)$ & 69.1 & 57.1 & \\
Distant disease & 2441 & 42.3 & 29.3 & 0.703 \\
$0--20 \mathrm{~mm}$ & $235(9.6)$ & 42 & 30.4 & \\
20--40 & $820(33.6)$ & 42.3 & 28.3 & \\
$>40$ & $1386(56.8)$ & 42.4 & 29.7 & \\
\hline
\end{tabular}

\section{Survival in patients who underwent surgery}

Among the 5424 patients, information regarding surgery was unknown in 15 cases. As a result, the remaining 5409 patients were enrolled for further study. Some 3041 patients underwent surgical
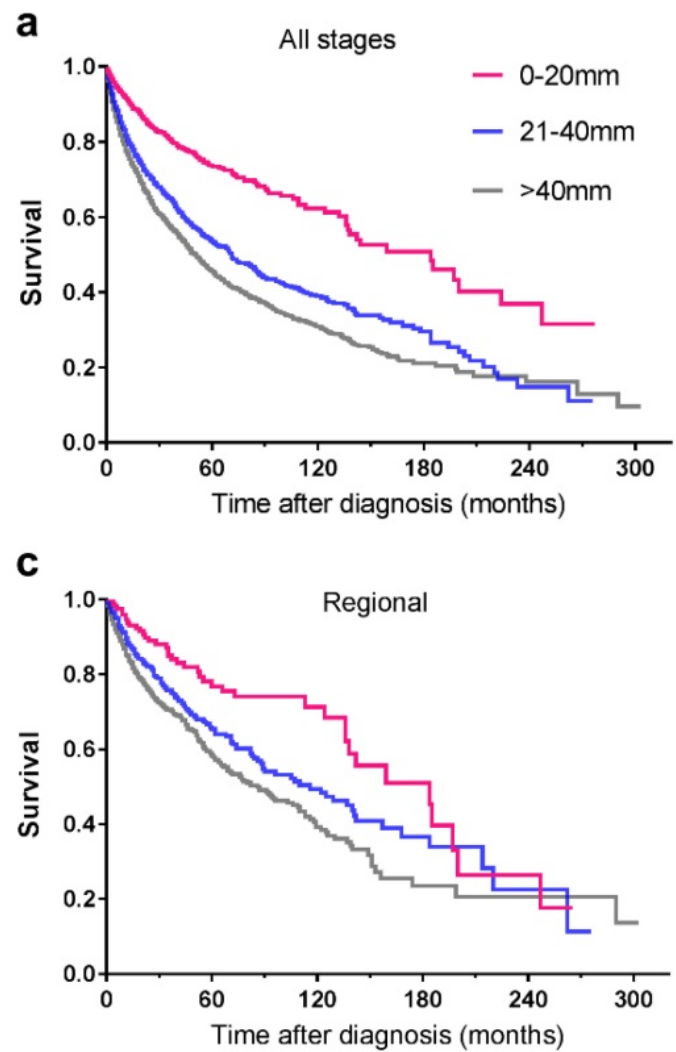

treatment, the 5-year survival rate of whom was $74.7 \%$ compared with $23.4 \%$ for patients who were not operated on. For patients with tumours $\leq 20 \mathrm{~mm}$, no matter surgery was performed or not, they had better survival than those with larger tumours (Table 4, Figure 4). In order to explore the significance of surgery on small PNETs, we performed a further study in patients with tumour size $\leq 20 \mathrm{~mm}$. For those who underwent surgery, the 3-year and 5-year survival rates were $90.5 \%$ and $85.6 \%$ respectively, absolutely more favorable compared with $46.6 \%$ and $33.9 \%$ for those who did not receive operation $(P<0.001)$ (Figure 5).

\section{Size and metastasis}

When pathologically confirmed tumours were classified into $10 \mathrm{~mm}$ size categories, there was a positive correlation between increasing tumour size and the probability of metastasis. Initially, it was analyzed with linear model, but we noted an obvious lack of fit. Then cubic spline analysis was used instead to generate a logistic curve, which was found to fit the data much better than the linear size (Figure 6). A multivariate logistic regression analysis revealed that a size increment of $1 \mathrm{~mm}$ was an independent prognostic factor for metastasis (HR=1.017, 95\% CI: $1.014-1.019, P<0.001)$.
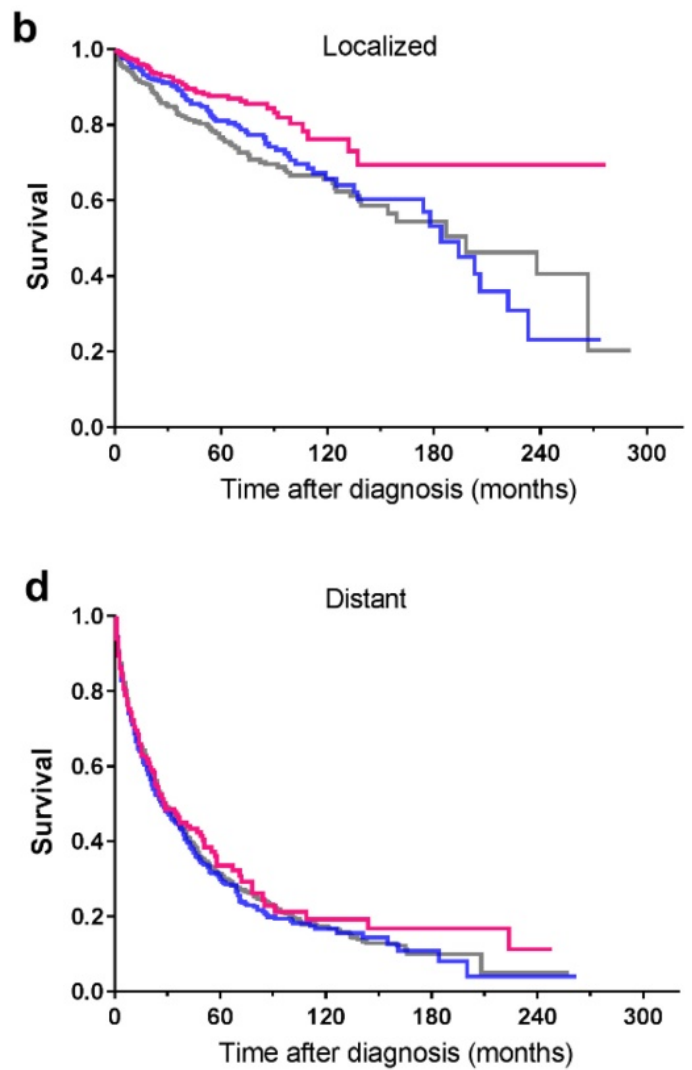

Figure 3. Kaplan-Meier survival curves illustrating survival by tumour size ( $\mathrm{mm})$ and stage of disease: a. all stages; b. localized; c. regional; d. distant 

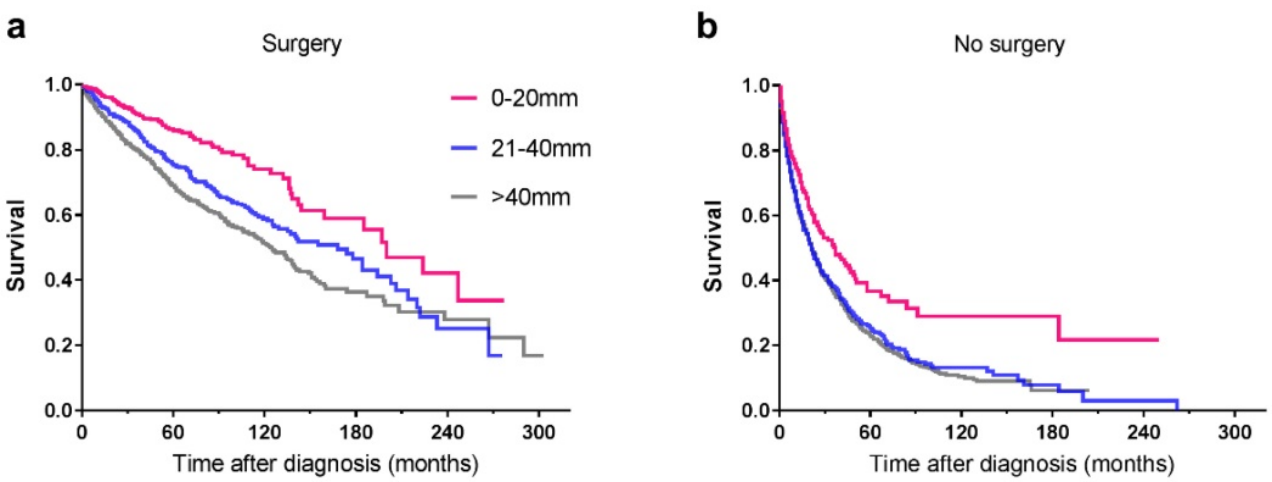

Figure 4. Kaplan-Meier curves of patients treated with (a) surgical resection and without (b) surgery, showing survival by tumour size.

Table 4. Subgroup analysis of survival by size, with or without surgical resection

\begin{tabular}{|c|c|c|c|c|c|c|c|}
\hline \multirow[t]{2}{*}{ Tumour size (mm) } & \multirow[t]{2}{*}{ No. of patients (5409) $(\%)$} & \multicolumn{2}{|c|}{ survival (\%) } & \multirow[t]{2}{*}{$P$ value } & \multirow[t]{2}{*}{ Hazard ratio } & \multirow[t]{2}{*}{$95 \% \mathrm{CI}$} & \multirow[t]{2}{*}{$P$ value } \\
\hline & & 3-year & 5-year & & & & \\
\hline Surgical resection & 3044 & 84.3 & 74.7 & $<0.001$ & & & \\
\hline $0--20$ & $906(30)$ & 90.5 & 85.6 & & 1 (reference) & & \\
\hline $21--40$ & $1010(33)$ & 84.9 & 74.5 & & 1.762 & $1.399-2.219$ & $<0.001$ \\
\hline$>40$ & $1128(37)$ & 79.5 & 68.8 & & 2.243 & $1.802-2.791$ & $<0.001$ \\
\hline No surgical resection & 2365 & 35.8 & 23.4 & $<0.001$ & & & \\
\hline 0--20 & $317(13.4)$ & 46.4 & 33.9 & & 1 (reference) & & \\
\hline $21--40$ & $791(33.4)$ & 35.8 & 23.8 & & 1.349 & $1.129-1.612$ & 0.001 \\
\hline$>40$ & $1257(53.2)$ & 33.6 & 21.3 & & 1.413 & $1.193-1.674$ & $<0.001$ \\
\hline
\end{tabular}

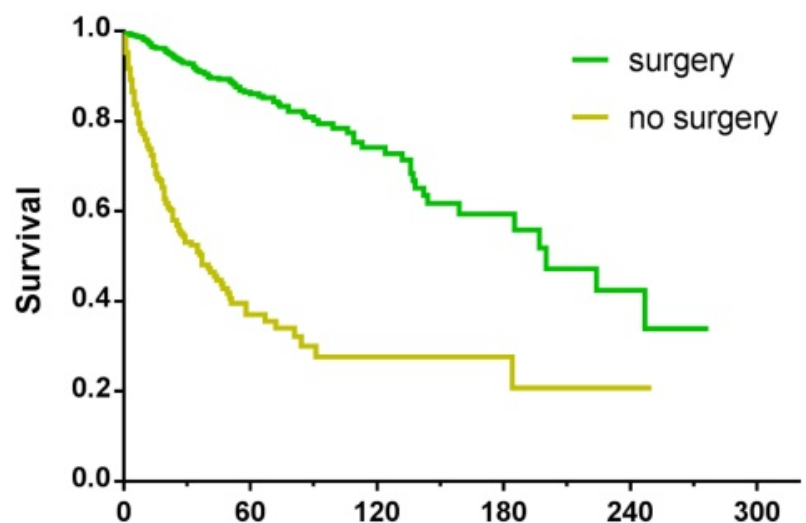

Figure 5. Kaplan-Meier survival curves of patients with tumour size $\leq 20 \mathrm{~mm}$, treated with or without surgery.

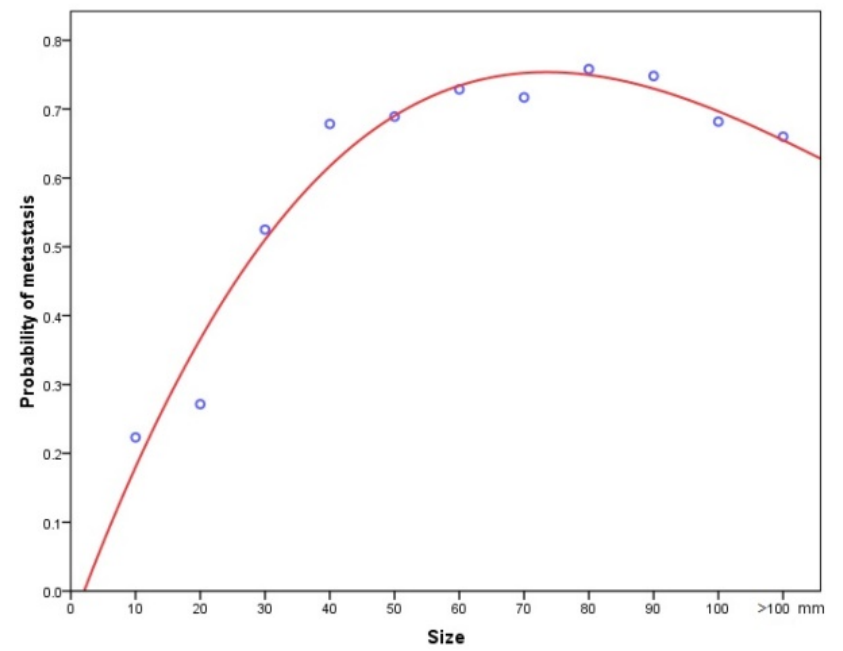

Figure 6. A cubic spline graph showing association between tumour size and the probability of metastasis.

\section{Characteristics of PNETs $\leq \mathbf{2 0} \mathrm{mm}$}

As shown in Table 2, we found that tumour sizes $20 \mathrm{~mm}$ was an indicator of good prognosis. In order to clarify the unique features of PNETs with size of $20 \mathrm{~mm}$ or less, its main parameters were compared with those of larger tumours. Among the identififed 5424 cases, 1226 tumours were $\leq 20 \mathrm{~mm}$ and 4198 were $>20 \mathrm{~mm}$. Demographic, clinical, and pathologic characteristics were summarized in Table 5. Briefly, most patients with tumour size $\leq 20 \mathrm{~mm}$ were well differentiated (52.8\%) and had localized disease (65.1\%), which both indicated good survival.

\section{Discussion}

The SEER program is an excellent tool for population analysis of malignancies, especially of rare diseases because of its data collection for over 30 years, extraordinary accuracy, and close approximation to the general US population[19]. Therefore, we conducted this study to elucidate some aspects of incidental trends, tumour characteristics and prognostic factors in patients with PNETs. Franko and his collegues have previously reported on PNETs using SEER data up to 2004[10]. However, they included only non-functional tumours with a smaller sample size and gave limited information. We herein provided an updated and more comprehensive evaluation of the incidence and prognosis of these uncommon tumours. The strength of our study is that 
the data include all patients diagnosed in a whole country over a 25 -year period. This eliminates the risk of inclusion bias or referral bias.

Table 5. Demographic and clinical characteristics of PNETs $\leq 20 \mathrm{~mm}$ versus $>20 \mathrm{~mm}$, SEER 1988-2013

\begin{tabular}{|c|c|c|c|}
\hline Characteristics & $\begin{array}{l}\text { Size } \leq 20 \mathrm{~mm} \\
\text { No. of patients } \\
(\%)(\mathrm{n}=1226)\end{array}$ & $\begin{array}{l}\text { Size }>20 \mathrm{~mm} \\
\text { No. of patients } \\
(\%)(\mathrm{n}=4198)\end{array}$ & $P$ value a \\
\hline \multicolumn{4}{|l|}{ Age (years) } \\
\hline$\leq 60$ & $601(49.0)$ & $2138(50.9)$ & \\
\hline$>60$ & $625(51.0)$ & $2060(49.1)$ & 0.240 \\
\hline \multicolumn{4}{|l|}{ Race/Ethnicity } \\
\hline White & $987(80.5)$ & $3377(80.4)$ & \\
\hline Black & 124(10.1) & $471(11.2)$ & \\
\hline Others & $115(9.4)$ & $350(8.3)$ & 0.323 \\
\hline \multicolumn{4}{|l|}{ Gender } \\
\hline Female & $621(50.7)$ & $1802(42.9)$ & \\
\hline Male & $605(49.3)$ & $2396(57.1)$ & $<0.001$ \\
\hline \multicolumn{4}{|l|}{ Histology } \\
\hline $\begin{array}{l}\text { Functional tumours } \\
(8150 \sim 8156)\end{array}$ & $224(18.3)$ & $921(21.9)$ & \\
\hline $\begin{array}{l}\text { Non-functional tumours } \\
(8240 \sim 8249)\end{array}$ & 1002(81.7) & $3277(76.9)$ & 0.006 \\
\hline \multicolumn{4}{|l|}{ Location of primary tumour } \\
\hline Head & $323(26.3)$ & $1495(35.6)$ & \\
\hline Body & $244(19.9)$ & $502(12.0)$ & \\
\hline Tail & $373(30.4)$ & $1314(31.3)$ & \\
\hline Others & $286(23.4)$ & $884(21.1)$ & $<0.001$ \\
\hline \multicolumn{4}{|l|}{ Grade } \\
\hline Well differentiated (I) & $647(52.8)$ & $1241(29.6)$ & \\
\hline $\begin{array}{l}\text { Moderately differentiated } \\
\text { (II) }\end{array}$ & $104(8.4)$ & $487(11.6)$ & \\
\hline Poorly differentiated (III) & $32(2.6)$ & $334(8.0)$ & \\
\hline Undifferentiated (IV) & $13(1.1)$ & $99(2.3)$ & \\
\hline Unknown & $430(35.1)$ & $2037(48.5)$ & $<0.001$ \\
\hline \multicolumn{4}{|l|}{ Tumour classification } \\
\hline Localized & $798(65.1)$ & $884(21.1)$ & \\
\hline Regional & 173(14.1) & $1039(24.8)$ & \\
\hline Distant & $235(19.2)$ & $2206(52.5)$ & \\
\hline Unknown & $20(1.6)$ & $69(1.6)$ & $<0.001$ \\
\hline \multicolumn{4}{|l|}{ Surgery } \\
\hline Yes & $906(73.9)$ & $2138(50.9)$ & \\
\hline No & $317(25.9)$ & 2048(48.8) & \\
\hline Unknown & $3(0.2)$ & $12(0.3)$ & $<0.001$ \\
\hline \multicolumn{4}{|l|}{ Regional lymph node } \\
\hline Positive & 141(11.5) & 1012(24.1) & \\
\hline Negative & $539(44.0)$ & $959(22.8)$ & \\
\hline Unknown & $546(44.5)$ & $2227(53.1)$ & $<0.001$ \\
\hline
\end{tabular}

The annual incidence of PNETs is nearly $3.01 / 100,000$ in the population, and this has been increasing over time. Consistent with previous studies $[8,10]$, we found that the majority of patients were men, white, and non-functional. The populations in our study showed a similar prognosis, with a 5 -year survival rate of $51.6 \%$. Not surprisingly, we observed that age, pathological grade, tumour stage, surgical treatment and tumour size were independent prognostic factors in multivariate analysis. Higher grade, more advanced stage, surgical treatment, higher age at diagnosis and larger tumour size were the strongest predictors of worse survival.
However, our analysis did not reveal any statistical differences in race, gender and tumour location, which is in keeping with the findings of other investigators[8,10]. Regarding the effect of functional status on survival, a majority of studies had reported a positive correlation. They found that patients with functional tumours had a more favorable prognosis than non-functional tumours[20,21,22]. However, in our study, there was no statistical significance of functionality on survival outcomes. This may be mostly attributed to the limitations of the SEER registry. The SEER registry did not provide data on the clinical presentation or laboratory values which were used to make the distinction between functional and non-functional tumours. We just used the histological codes to determine the functionality of PNETs, which relied on pathology reports supplied by the participating institutions, and this gave rise to a potential for misclassification of these tumours. Another important reason was that the SEER registry excluded PNETs considered to be benign, which consisted of a number of functional tumours and manifested a quite favorable prognosis.

Traditionally, it is recognized that the presence of lymph nodes has negative impact on survival. However, whether it is an prognostic factor has always been conflicting, as different investigations giving different results[14] . A number of studies reported that lymph node status had important prognostic value $[9,23,24,25,26]$. However, other reports failed to detect a survival difference in those with lymph node diseases[27,28,29]. In the current study, we also found that lymph node involvement had no effect on survival. As this is an important management point because it has a direct influence on the type of and extent of surgical procedure that should be performed, more investigations, especially larger and prospective, are demanded.

Tumour size is a readily available parameter, can be accurately measured and has the great advantage of little discrepancy among observers. Its prognostic value in PNETs has been investigated extensively $[8,9,10,30,31,32,33]$. Although the results beween different studies were inconsistent, tumour size was used as a criterion of staging in the AJCC and ENETS system[6,7]. In the present study, we demonstrated that tumour size was an independent prognostic factor for survival among patients with PNETs, on both univariate and multivariate analysis. More precisely than before, we revealed a stage-dependent relationship between tumour size and survival. The association between small tumour size and prolonged survival was confirmed in the subgroups of patients with localized and regional cancers. Once the cancer had disseminated, tumour size was no longer an 
important predictive factor for long-term survival. The possible reason may be that for distant disease, patients already had metastasis, thus the influence of tumour size on their prognosis was likely outweighed by the dismal outcomes associated with the pre-existing metastatic disease. Furthermore, we provided the first evidence that increasing tumour size was associated with a higher probability of metastasis in a nationwide registry, starting at $13 \%$ for tumours $10 \mathrm{~mm}$ or less and attaining $52 \%$ for tumours greater than $90 \mathrm{~mm}$. A nonlinear relationship was noted, with a sickle shape. The possible explanation was the propensity and opportunity of individual cells in a tumour to metastasize. In smaller tumours, by contact with adjacent structures, the odds for cells to gain access to vascular or lymphatic channels increased, which consequently lead to dissemination. While, in larger tumours, central necrosis, due to the lack of a stable blood supply, may contributed greatly to the decreased proportion of metastatic rate, which account for the sickle shape that we observed.

Regarding PNETs $\leq 20 \mathrm{~mm}$, some prior reports found that the proportion of these patients has nearly doubled over the last 22 years[11]. This increase was probably because of the frequent use of axial imaging and endoscopic ultrasound. For these patients, an aggressive surgical approach has long been the rule[34,35]. However, despite its increasing safety, surgical resection has recently been challenged because of its lack of proven effect on long-term survival[36,37]. Thus, the optimal treatment for these patients became controversial. Recently, for this subgroup of lesions, a wait-and-see policy has been advocated[38]. Nevertherless, we herein showed that patients with PNETs $\leq 20 \mathrm{~mm}$ who undergo surgery demonstrate a distinct survival benefit compared with their unresected peers. So we still recommended surgery as the preferred treatment for these patients.

Our present study had some limitations. First, it was retrospective and had the general weakness of this study design. Second, as a population-based registry, the SEER database could have coding errors inevitably, and it provided a large sample size at the expense of loss of clinical details. Third, in order to classify the tumour stage, the SEER historical stage A was used, which was different from the AJCC staging system and probably of less clinical relevance. However, these classifications were available for most individuals and keep consistent during the whole study period.

Despite the above limitations, our findings brought important clinical values. This large population-based study provided an up-to-date estimate of the incidence data as well as clinicopathological characteristics and survival analysis of PNETs. It suggested that tumour size correlated strongly with the rate of metastasis and was an independent prognostic factor of survival after adjusting for confounding variables. Surgical treatment was preferably recommended for PNETs, including patients with tumour size $\leq 20 \mathrm{~mm}$.

\section{Acknowledgments}

The authors acknowledge the efforts of the Surveillance, Epidemiology, and End Results Program tumor registries in the creation of the SEER database.

\section{Funding Support}

This work was supported by Science and Technology Plan of Medicine and Health of Zhejiang Province (2019321977), the National Natural Science Foundation of China (81472214), the Key Science and Technology Innovation Team of Lishui City (2018cxtd 05), the Public Welfare Technology Research Program of Lishui City (2019SJZC49) , National Key R\&D Program of China (2016YFC1303200 and 2016YFC010 7003).

\section{Author contributions}

Liangjing Wang and Yangyang Liu made substantial contributions to the conception and design of this study; Yangyang Liu, Xingkang He, Yabi Zhu and Shufang Ye analyzed and interpreted the data; Yangyang Liu and Jie Pan wrote the manuscript; Liangjing Wang and Bin Ye revised the manuscript for important intellectual content; Lianging Wang and Yangyang Liu gave final approval to submit the manuscript for publication.

\section{Competing Interests}

The authors have declared that no competing interest exists.

\section{References}

[1] Modlin IM, Oberg K, Chung DC, et al . Gastroenteropancreatic neuroendocrine tumours. Lancet Oncol. 2008;9(1):61-72.

[2] Fraenkel M, Kim MK, Faggiano A, et al. Epidemiology of gastroenteropancreatic neuroendocrine tumours. Best Pract Res Clin Gastroenterology. 2012;26(6):691-703.

[3] Lawrence B, Gustafsson BI, Chan A, et al. The epidemiology of gastroenteropancreatic neuroendocrine tumors. Endocrinol Metab Clin North Am. 2011;40(1):1-18.

[4] McKenna LR, Edil BH. Update on pancreatic neuroendocrine tumours. Gland Surg. 2014;3(4): 258-275.

[5] Metz DC, Jensen RT. Gastrointestinal neuroendocrine tumors: pancreatic endocrine tumors. Gastroenterology. 2008;135(5):1469-1492.

[6] Rindi G, Kloppel G, Alhman H, et al; all other Frascati Consensus Conference participants; European Neuroendocrine Tumor Society (ENETS). TNM staging of foregut (neuro)endocrine tumors: A consensus proposal including a grading system. Virchows Arch. 2006; 449(4):395-401.

[7] Edge SB, Byrd DR, Compton CC, et al. editors (2010) AJCC Cancer Staging Manual (ed 7). New York, NY: Springer.

[8] Bilimoria KY, Tomlinson JS, Merkow RP, et al. Clinicopathologic features and treatment trends of pancreatic neuroendocrine tumors: analysis of 9,821 patients. J Gastrointest Surg. 2007; 11(11):1460-1467. 
[9] Jin K, Luo G, Xu J, et al. Clinical outcomes and prognostic factors of resected pancreatic neuroendocrine neoplasms: A single-center experience in China. Oncology Letters. 2017;13(5): 3163-3168.

[10] Franko J, Feng W, Yip L, et al. Non-functional Neuroendocrine Carcinoma of the Pancreas: Incidence, Tumor Biology, and Outcomes in 2,158 Patients. J Gastrointest Surg. 2010;14(3):541-548.

[11] Kuo EJ, Salem RR. Population-level analysis of pancreatic neuroendocrine tumours 2cm or less in size. Ann Surg Oncol. 2013;20(9):2815-2821.

[12] Hill JS, Mc Phee JT, Mc Date TP, et al. Pancreatic neuroendocrine tumours: The impact of surgical resection on survival. Cancer. 2009;115(4):741-751.

[13] Haugvik SP, Janson ET, osterlund P, et al. Surgical treatment as a principle for patients with high-grade pancreatic neuroendocrine carcinoma: A nordic multicenter comparative study. Ann Surg Oncol. 2016;23(5):1721-1728.

[14] Falconi M, Eriksson B, Kaltsasc G, et al. all other Vienna Consensus Conference participants. Consensus guidelines update for the management of functional p-NETs (F-p-NETs) and non-functional p-NETs (NF-p-NETs). Neuroendocrinology. 2016;103(2):153-171.

[15] Crippa S, Partelli S, Zamboni G, et al. Incidental diagnosis as prognostic factor in different tumor stages of nonfunctioning pancreatic endocrine tumors. Surgery. 2014;155(1):145-153.

[16] Cheema A, Weber J, Strosberg JR. Incidental detection of pancreatic neuroendocrine tumors: an analysis of incidence and outcomes. Ann Surg Oncol. 2012;19(9):2932-2936.

[17] Gaujoux S, Partelli S, Maire F, et al. Observational study of natural history of small sporadic nonfunctioning pancreatic neuroendocrine tumors. J Clin Endocrinol Metab. 2013;98(12):4784-4789.

[18] de Mestier L, Gaujoux S, Cros J, et al. Long-term Prognosis of Resected Pancreatic Neuroendocrine Tumors in von Hippel-Lindau Disease Is Favorable and Not Influenced by Small Tumors Left in Place. Ann Surg. 2015;262(2):384-388.

[19] National Cancer Institute Surveillance, Epdemiology, and End Results Program. SEER $*$ Stat Database: Incidence-SEER 18 Regs Custom Data (with chemotherapy recode), Nov 2015 Sub (1973-2013 varying). https://seer.cancer.gov/ seerstat/ [accessed 25 July 2016].

[20] Garcia-Carbonero R, Capdevila J, Crespo-Herrero G, et al. Incidence, patterns of care and prognostic factors for outcome of gastroenteropancreatic neuroendocrine tumors (GEP-NETs): results from the National Cancer Registry of Spain (RGETNE). Ann Oncol. 2010;21(9): 1794-1803.

[21] Yao JC, Hassan M, Phan A, et al. One hundred years after "carcinoid": epidemiology of and prognostic factors for neuroendocrine tumors in 35,825 cases in the United States. J Clin Oncol. 2008;26(18):3063-3072.

[22] Bilimoria KY, Talamonti MS, Tomlinson JS, et al. Prognostic score predicting survival after resection of pancreatic neuroendocrine tumors: analysis of 3851 patients. Ann Surg. 2008;247(3): 490-500.

[23] $\mathrm{Xu} \quad \mathrm{H}, \mathrm{Xu} \quad \mathrm{X}$, Jin $\mathrm{D}$, et al. Clinicopathological characteristics and prognosis-related factors of resectable pancreatic neuroendocrinetumors: a retrospective study of 104 cases in a single Chinese center. Pancreas. 2014;43(4):526-531.

[24] Hashim YM, Trinkaus KM, Linehan DC, et al. Regional lymphadenectomy is indicated in the surgical treatment of pancreatic neuroendocrine tumors (PNETs). Ann Surg. 2014:259 (2):197-203.

[25] Ricci C, Casadei R, Taffurelli G, et al. The role of lymph node ratio in recurrence after curative surgery for pancreatic endocrine tumours. Pancreatology. 2013;13(6):589-593.

[26] Tsutsumi K, Ohtsuka T, Mori $Y$, et al. Analysis of lymph node metastasis in pancreatic neuroendocrine tumors (PNETs) based on the tumor size and hormonal production. J Gastroenterol. 2012;47(6):678-685.

[27] Boyar C R, Vatn M, Aabakken L, et al. Survival and prognostic factors in well-differentiated pancreatic neuroendocrine tumors. Scandinavian Journal of Gastroenterology. 2014;49(6): 734-741.

[28] Cherenfant J, Stocker SJ, Gage MK, et al. Predicting aggressive behavior in nonfunctioning pancreatic neuroendocrine tumors. Surgery. 2013;154(4):785-793.

[29] Bilimoria KY, Bentrem DJ, Merkow RP, et al. Application of the pancreatic adenocarcinoma staging system to pancreatic neuroendocrine tumors. J Am Coll Surg. 2007;205(4):558-563.

[30] Tomassetti P, Campana D, Piscitelli L, et al. Endocrine pancreatic tumors: factors correlated with survival. Ann Onco. 2005;116(11):1806-1810.

[31] Bettini R, Partelli S, Boninsegna L, et al. Tumor size correlates with malignancy in nonfunctioning pancreatic endocrine tumor. Surgery. 2011;150(1):75-82.

[32] Bettini R, Boninsegna L, Mantovani W, et al. Prognostic factors at diagnosis and value of WHO classification in a mono-institutional series of 180 non-functioning pancreatic endocrine tumours. Ann Oncol. 2008;19(5):903-908.

[33] Gullo L, Migliori M, Falconi M, et al. Nonfunctioning pancreatic endocrine tumours: a multicenter clinical study. Am J Gastroenterol. 2003;98(11):2435-2439.

[34] Kim MJ, Choi DW, Choi SH, et al. Surgical strategies for non-functioning pancreatic neuroendocrine tumours. Br J Surg. 2012;99(11):1562-1568.

[35] Schurr PG, Strate T, Rese K, et al. Aggressive surgery improves long-term survival in neuroendocrine pancreatic tumors: an institutional experience. Ann Surg. 2007;245(2):273-281.

[36] Haynes $A B$, Deshpande V, Ingkakul $T$, et al. Implications of incidentally discovered, nonfunctioning pancreatic endocrine tumors: short-term and long-term patient outcomes. Arch Surg. 2011;146(5):534-538.
[37] Cheema A, Weber J, Strosberg JR. Incidental detection of pancreatic neuroendocrine tumors: ananalysis of incidence and outcomes. Ann Surg Oncol. 2012;19(9):2932-2936.

[38] Lee LC, Grant CS, Salomao DR, et al. Small, nonfunctioning, asymptomatic pancreatic neuroendocrine tumors (PNETs): role for nonoperative management. Surgery. 2012;152(6):965-974. 